\title{
Level Control of Two Conical Tank Non Interacting System using PID and Fuzzy Logic
}

\author{
Immanuvel Davis ${ }^{1}$, Jishnu CP², Raheja William ${ }^{3}$, Silpa Krishnan ${ }^{4}$, Sumith KP ${ }^{5}$, Ms. K. Neethu Sathyan ${ }^{6}$ \\ UG Scholar, Electronics and Communication, IES College of Engineering, Thrissur, India ${ }^{1,2,3,4,5}$
}

Asst. Professor, Electronics and Communication, IES College of Engineering, Thrissur, India ${ }^{6}$

\begin{abstract}
Non-linear process control is a difficult problem in process industries. Conical tank level control is one among them. Conical tanks are widely used in many industries due to its shape which provides easy discharge of water when compared to other tanks. Moreover, liquid level control of a conical tank is still challenging for typical process control because of its nonlinearities by a reason of constantly changing cross section area. By using fuzzy logic, designers can realize lower development costs, superior features, and better end product performance. Fuzzy is often the very best way as they are faster and cheaper. One of successful application that used fuzzy control is liquid tank level control. The purpose of this project is to design a simulation system of fuzzy logic controller for liquid tank level control by using simulation package which is Fuzzy Logic Toolbox and Simulink in MATLAB software. In this paper the mathematical modeling of two non-interacting conical tanks by PID controller and fuzzy. In this paper, we take the liquid level water tank, and use MATLAB to design a Fuzzy Control. Then we analyze the control effect and compare it with the effect of PID controller. As a result of comparing, Fuzzy Control is superior to PID control. Especially it can give more attention to various parameters, such as the time of response, the error of steadying and overshoot. Comparison of the control results from these two systems indicated that the fuzzy logic controller significantly reduced overshoot and steady state error.
\end{abstract}

Keywords: Conical Tank, Level Control, Fuzzy Logic Toolbox, Simulink, MATLAB.

\section{INTRODUCTION}

In process industries, primary task of any controller is to overcome various disturbances to make the process to remain in stable condition. In any process tank, shape plays a vital role for designing the controllers. In this paper we have considered a conical tank because of the following advantages like better disposal of solids, easy mixing, and complete drainage of solvents such as viscous liquids in industries.

The controller has to be chosen based on its non-linearity. In conical tank non-linearity exists due to its variations in cross-sectional area. Level control of the conical tank is a challenging task and it demands for implementation in real time.

Conventional PID controllers are simple, robust provided the system is linear. But the process considered here has nonlinear characteristics which is represented as piecewise linearized models. Industries use mainly conventional controller i.e., PID (Proportional Integral Derivative) controller because of their performance and hence it is called as work-horse of process industries. But in level controlling task of conical tank, PID fails to give fast response because of the non - linearity present in the system. To overcome this drawback, we are using a heuristic method based controller called Fuzzy Logic Controller

\section{EXISTING SYSTEM}

The control of liquid level in tank and flow in the tank is a basic problem in process industries. The process industries require the liquids to be pumped, stored in tanks and then pumped to another tank. Many times the liquid will be processed by chemical or mixing treatment in the tanks, but always the level of the fluid in the tanks must be controlled. Controlling of liquid level is an important and common task in process industries, in this level process the tank is conical shape in which the level of liquid is desired to maintain at a constant value. This is achieved by controlling the input flow into the tank.

The control variable is the level in a tank and the manipulated variable is the inflow to the tank. Conical tanks find wide applications in process industries, namely hydrometallurgical industries, food process industries, concrete mixing industries and wastewater treatment industries. 


\section{International Journal of Innovative Research in Electrical, Electronics, Instrumentation and Control Engineering \\ ISO 3297:2007 Certified \\ Vol. 5, Issue 4, April 2017}

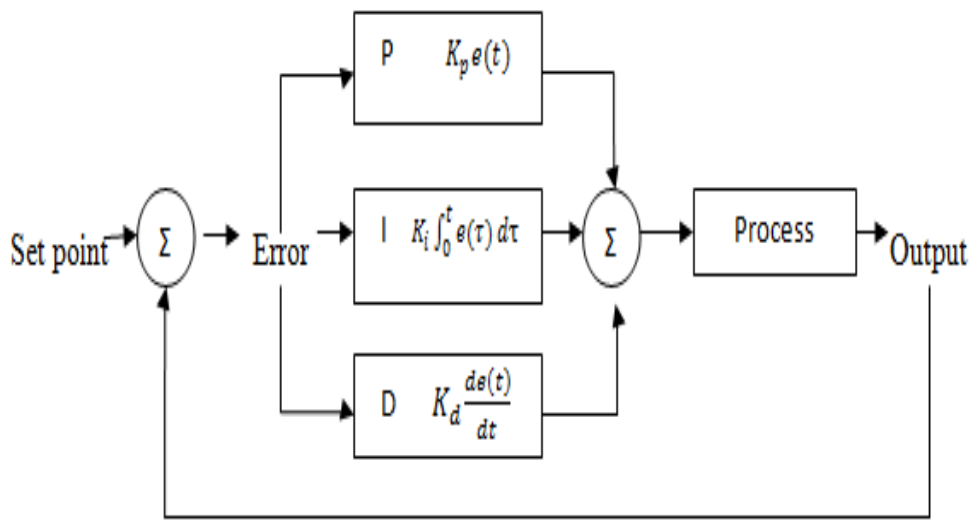

Fig.2Block diagram of closed loop system

\section{PROPOSED SYSTEM}

A real time experimental setup for extremely non-linear conical tank is constructed. The process control system is interfaced using PCI 6221 DAQ module to the personal computer. The block diagram for this system is shown in Fig 3, it consists of a controller, driver circuit used to operate the solenoid valve, nonlinear conical tank, capacitance based level sensor and signal conditioning unit.

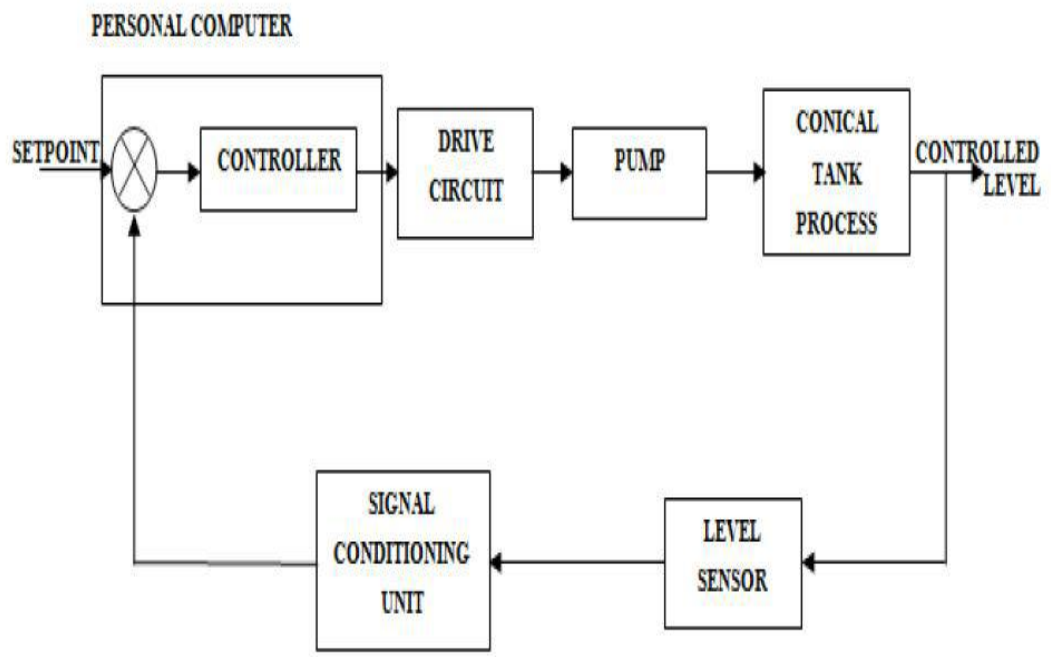

Fig.3 Block diagram of proposed system

\section{SOFTWARE DESCRIPTION}

Simulink is a software package and is a graphical extension of MATLAB for modelling, simulating and analyzing a variety of dynamical systems under a Graphical User Interface (GUI) environment. Different blocks are then connected as per the model requirement by arranging them and drawing connecting lines from the output terminal of one block to the input terminal of the other block.

The various steps to make a complete model are as follows:

1. Collecting blocks to create a model

2. Modifying block parameters

3. Labeling blocks

4. Connecting blocks

5. Labeling the signal lines

6. Saving the model 


\section{International Journal of Innovative Research in} Electrical, Electronics, Instrumentation and Control Engineering

ISO 3297:2007 Certified

Vol. 5, Issue 4, April 2017

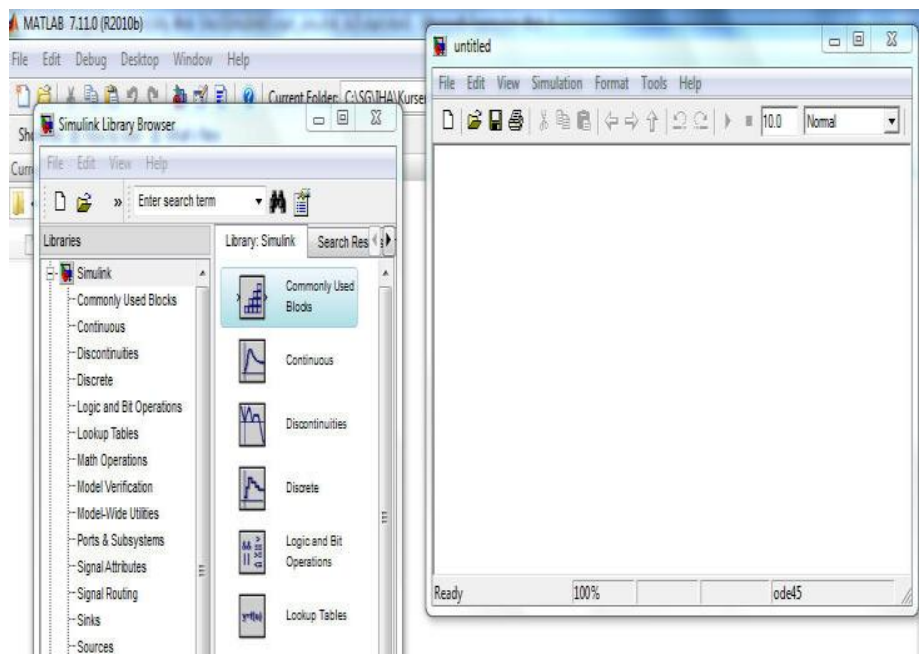

Fig.4(a) New Untitled Simulink Window

Fuzzy Logic is basically a multi-valued logic that allows intermediate values to be defined between conventional evaluations like yes/no, true/false and black/white. Notions like warm cold or very cold can be formulated mathematically and processed by computers.

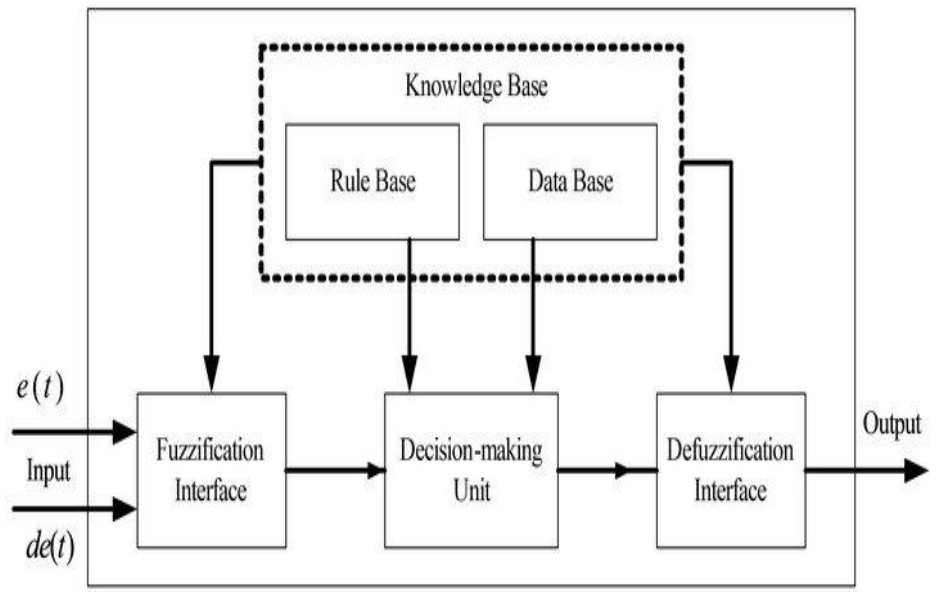

Fig.4(b) Block diagram of fuzzy logic controller

Mainly FLC are implemented on non-linear systems which yield for better results. For designing the controller number of parameters needs to be selected and then Membership Function and rules are selected based on heuristic knowledge.

\section{MATHEMATICAL MODELING OF TWO CONICAL TANKS OF NON-INTERACTING SYSTEM}

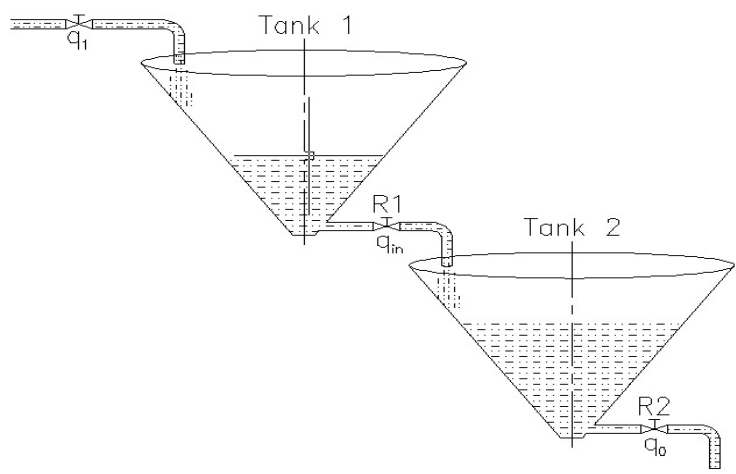

Fig. 5Two Conical Tanks of Non-Interacting System 


\section{IJIREEICE \\ International Journal of Innovative Research in \\ Electrical, Electronics, Instrumentation and Control Engineering \\ ISO 3297:2007 Certified \\ Vol. 5, Issue 4, April 2017}

According to law of conservation of mass,

Accumulation of mass within a system $=$ Flow of mass into the system - Flow of mass out to the system.

$$
\begin{aligned}
& \mathrm{V} 1 * \frac{\mathrm{dh} 1}{\mathrm{dt}}=\mathrm{q}_{\text {in }}-\mathrm{q}_{1} \\
& \frac{\mathrm{h}_{1}(\mathrm{~s})}{\mathrm{q}_{\text {in }}(\mathrm{s})}=\frac{\mathrm{R}_{1}}{\mathrm{sR}_{1} \mathrm{~V}_{1}(\mathrm{~s})+1} \\
&=\frac{\mathrm{K}_{\mathrm{p}}}{\tau_{1} \mathrm{~s}+1}
\end{aligned}
$$

For a combined tank with $\mathrm{q}_{\mathrm{in}}(\mathrm{s})$ and $\mathrm{q}_{\mathrm{o}}(\mathrm{s})$ as inflow and outflow parameters, then the overall transfer function is given by

$$
\frac{\mathrm{q}_{\mathrm{o}}(\mathrm{s})}{\mathrm{q}_{\text {in }}(\mathrm{s})}=\frac{1}{\left(\tau_{1} \mathrm{~s}+1\right)\left(\tau_{2} \mathrm{~s}+1\right)}
$$

For a real process the transfer function of non-interacting conical tank system is given by,

$$
\frac{\mathrm{q}_{\mathrm{o}}(\mathrm{s})}{\mathrm{q}_{\text {in }}(\mathrm{s})}=\frac{378}{5751.71 \mathrm{~s}^{2}+341.28 \mathrm{~s}+378}
$$

\section{STEPS FOR SIMULATION OF PID}

Open a new MATLAB Simulink model.

$>$ Arrange the blocks and do the modeling as per block diagram.

$>$ Add PID controller gain by giving the values of $\mathrm{Kp}, \mathrm{Ki}, \mathrm{Kd}$.

$>$ Simulate it and provide step input as set point \& observe the output.

$>$ Compare the result with that of the response from Fuzzy Logic Controller.

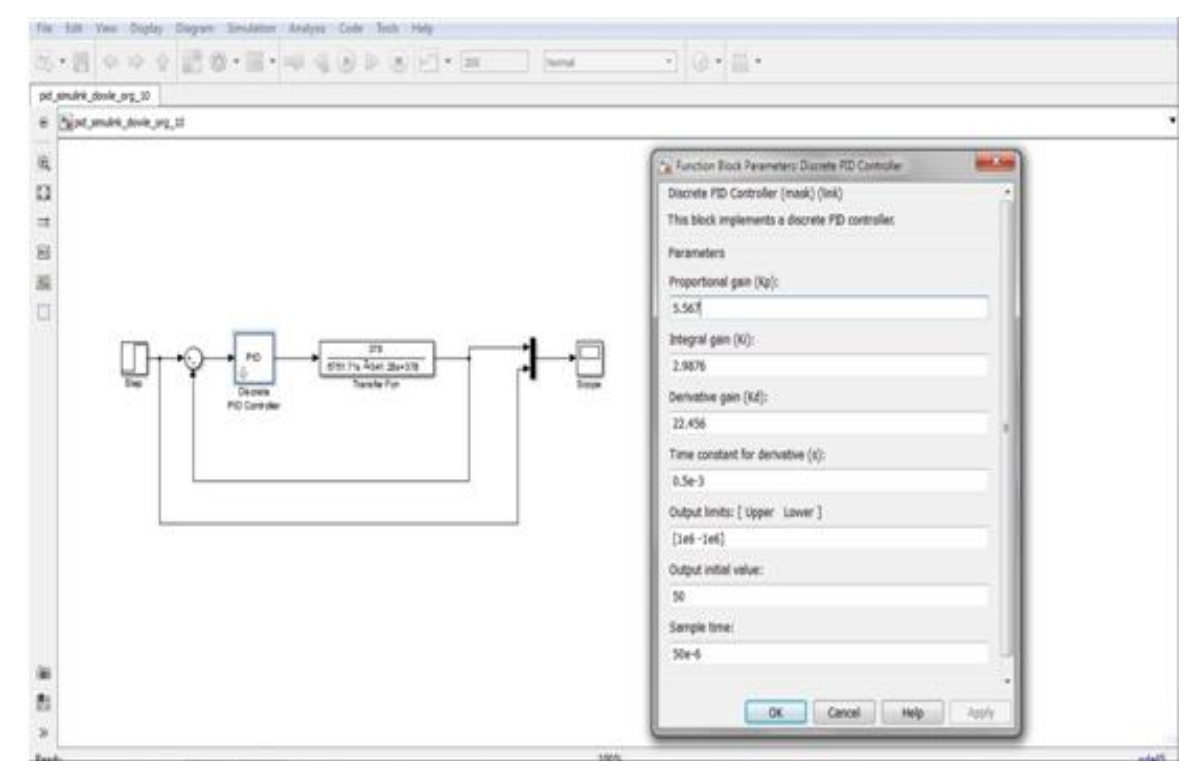

Fig.6(a) Simulink model for two conical tank using PID controller

\section{STEPS FOR SIMULATION OF FUZZY LOGIC CONTROLLER}

Click on the MATLAB icon.

$>$ In command window type "fuzzy", this opens the FIS editor window.

Name the input and output fuzzy set.

$>$ Click on the input and output membership functions.

$>$ In the FIS editor click on the rule base to get the Rule editor.

$>$ Define the "If-Then" rules in the rule editor.

Take View > Rules to get the Rule Viewer.

$>$ Now for different values of input, see the corresponding output in the rule viewer (depends on the defuzification rule) 
International Journal of Innovative Research in Electrical, Electronics, Instrumentation and Control Engineering ISO 3297:2007 Certified

Vol. 5, Issue 4, April 2017

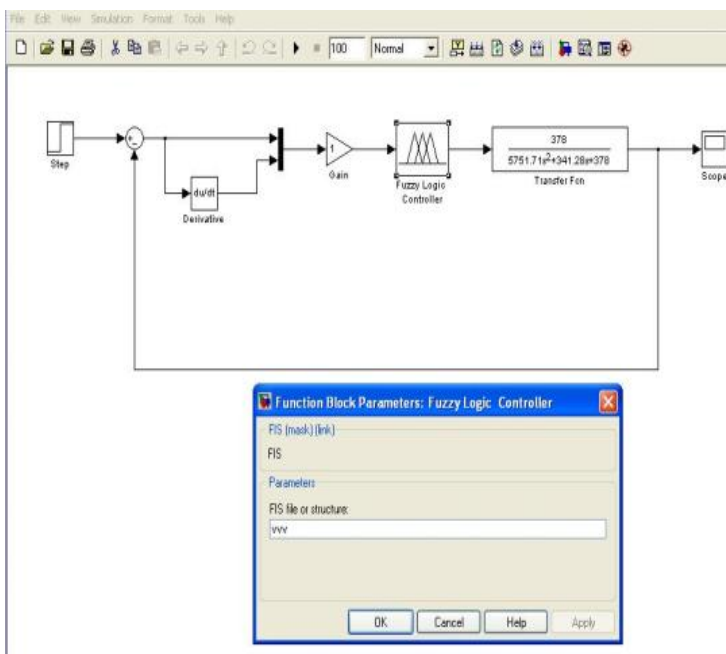

Fig.7(a) Simulink model two tank system using Fuzzy Logic Controller

\begin{tabular}{|c|c|c|c|c|c|c|c|}
\hline ee & NB & NM & NS & $Z$ & PS & PM & PB \\
\hline NB & NB & NB & NB & NM & NS & NS & $Z$ \\
\hline NM & NB & NB & NM & NS & NS & $Z$ & PS \\
\hline NS & NB & NM & NS & NS & $Z$ & PS & PM \\
\hline$Z$ & NM & NM & NS & $Z$ & PS & PM & PM \\
\hline PS & NM & NS & Z & PS & PS & PM & PB \\
\hline PM & NS & $Z$ & PS & PS & PM & PB & PB \\
\hline PB & $Z$ & PS & PS & PM & PB & PB & PB \\
\hline
\end{tabular}

Fuzzy logic rules for two tank system

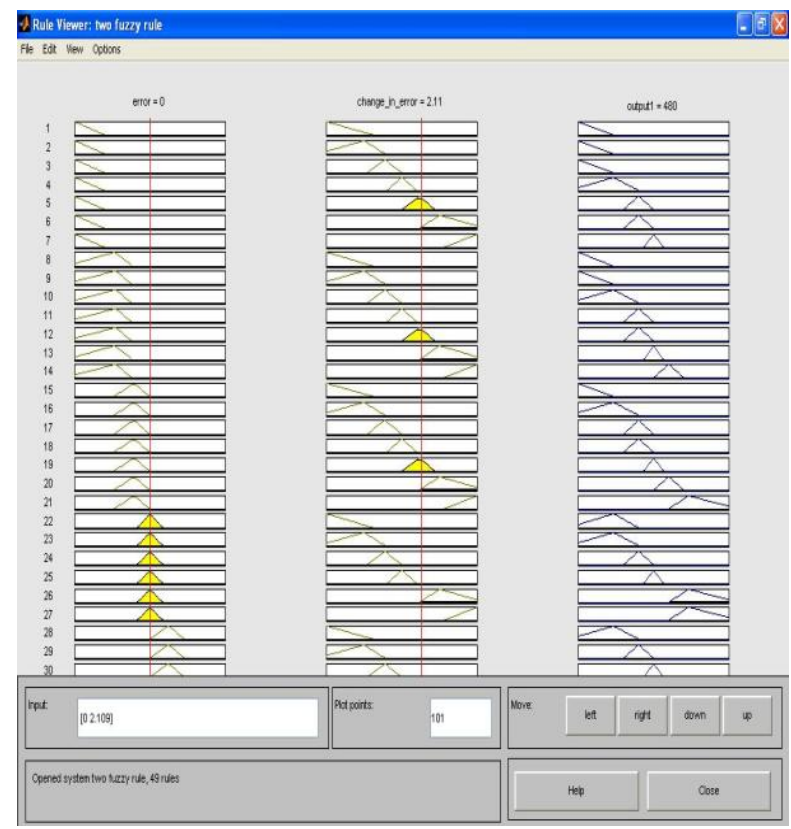

Fig.7(b) Response of Fuzzy Logic Controller Using Rule Viewer 


\section{International Journal of Innovative Research in}

Electrical, Electronics, Instrumentation and Control Engineering

ISO 3297:2007 Certified

Vol. 5, Issue 4, April 2017

\section{VIII.STEPS FOR EXPORTING FUZZY OUTPUT TO SIMULINK WORKSPACE}

Go to FIS editor $>$ File $>$ Export $>$ to workspace.

$>$ Save as workspace variable ['vvv'].

$>$ Minimize the window.

> Go to MATLAB > Simulink > Library browser > Fuzzy logic tool bar.

$>$ Drag Fuzzy Logic Controller with rule viewer to block diagram and complete the connection s shown in the Fig .7.11.

Double click on the icon of Fuzzy Logic Controller and give the name as 'vvv'.

$>$ Simulate it and compare the response with that of PID controller.

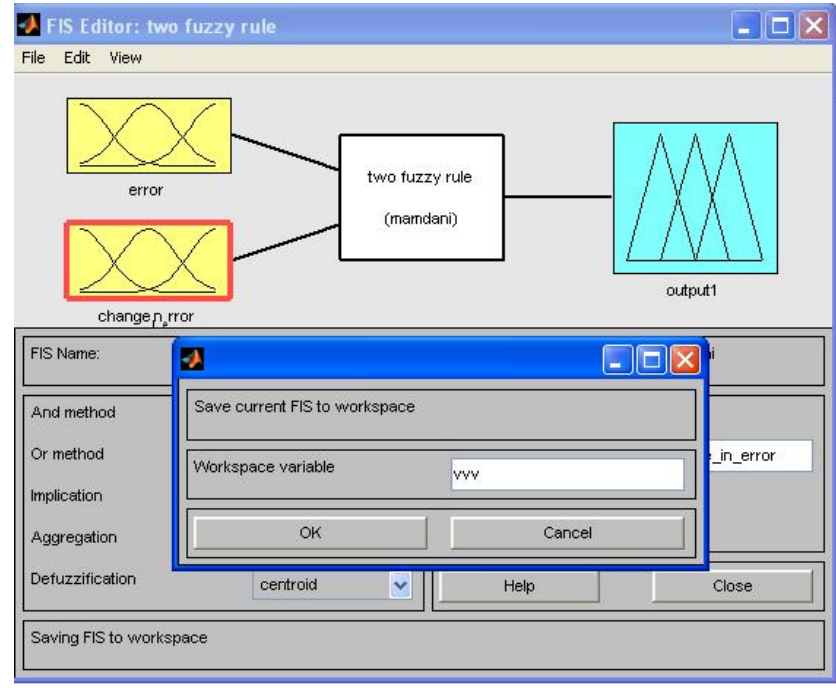

Fig. 8Exporting to workspace

\section{RESULTS}

The simulation is carried out using MATLAB Simulink. The response of two conical tank non interacting system using PID and Fuzzy Logic Controller is given in Fig 9(a) and Fig 9(b).After comparing the graphs of conventional PID and fuzzy logic controller as shown in Fig.8.1 and Fig.8.2, it is clear that fuzzy logic has small overshoot and is having the fast response as compared to conventional PID Controller. Then, various time domain specifications of both the controllers are compared such as:

- Rise Time

- $\quad$ Settling Time

- Overshoot

- Transient Behavior

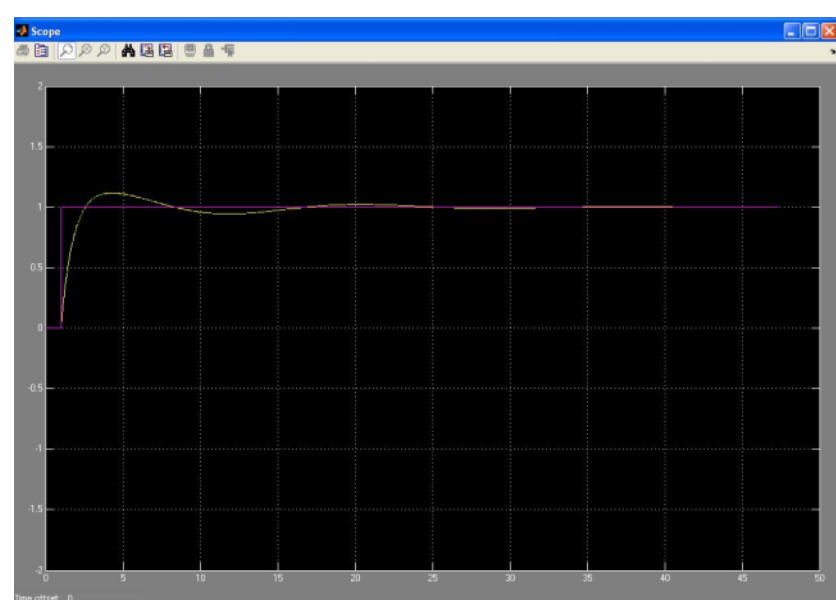

Fig.9(a) Simulation response of two tank system using PID controller 
International Journal of Innovative Research in

Electrical, Electronics, Instrumentation and Control Engineering

ISO 3297:2007 Certified

Vol. 5, Issue 4, April 2017

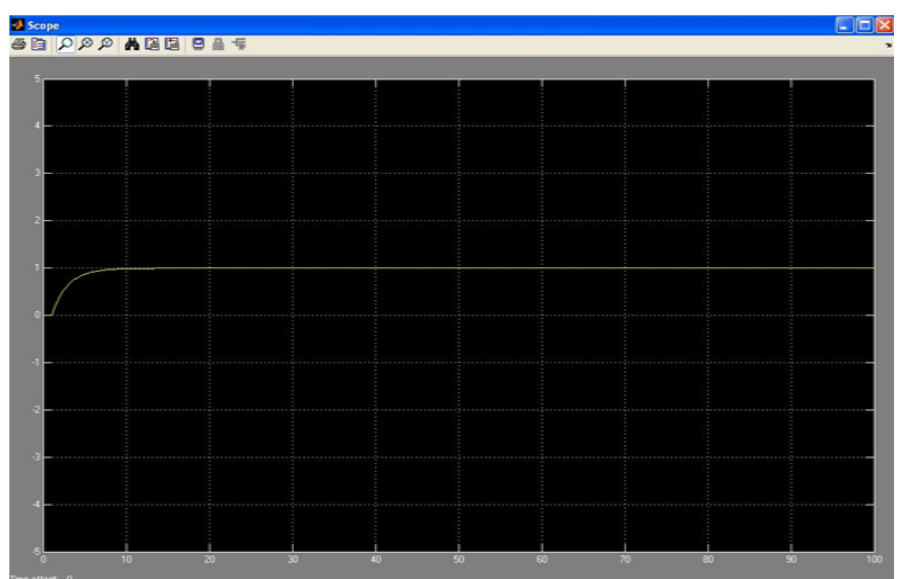

Fig.9(b) Simulation response of two tank system using Fuzzy Logic Controller

Comparison between PID and FLC

\begin{tabular}{|c|c|c|}
\hline PARAMETERS & PID & FLC \\
\hline Overshoot & Present & Not Present \\
\hline Settling Time & $24 \mathrm{sec}$ & $8 \mathrm{sec}$ \\
\hline Transient Behavior & Oscillatory & Smooth \\
\hline Rise Time & $3 \mathrm{sec}$ & $2 \mathrm{sec}$ \\
\hline
\end{tabular}

\section{CONCLUSION}

The advantages of a fuzzy based controller over a PID controller are derived from results. Better control performance, robustness and overall stability can be expected from the fuzzy controller. Fuzzy controllers have better stability, small overshoot, and fast response. Hence, fuzzy logic controller is introduced for controlling fluid flows

\section{REFERENCES}

[1] Dharamniwas and Aziz AhmadandVarunRedhu and Umesh Gupta-"Liquid level control by using fuzzy logic controller"

[2] P.Aravind, M.Valluvan, S.Ranganathan-"Modelling and Simulation of Non Linear Tank"

[3] S.Saju, R.Revathi, K.ParkaviSuganya-"Modeling and Control of Liquid Level Non-linearInteracting and Non-interacting System"

[4] Raj Kumar Bansal, Ashok Kumar Goel, Manoj Kumar Sharma-"MATLAB and its applications in engineering”.

\section{BIOGRAPHIES}

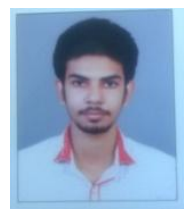

Immanuvel Davis currently pursuing the Bachelor's degree in Applied Electronics \& Instrumentation Engineering from the IES College of Engineering, Thrissur.

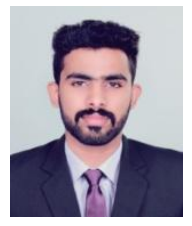

Jishnu CP currently pursuing the Bachelor's degree in Applied Electronics \& Instrumentation Engineering from the IES College of Engineering, Thrissur.

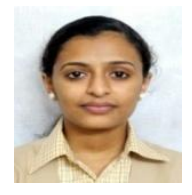

Raheja William currently pursuing the Bachelor's degree in Applied Electronics \& Instrumentation Engineering from the IES College of Engineering, Thrissur. 


\section{International Journal of Innovative Research in}

Electrical, Electronics, Instrumentation and Control Engineering

ISO 3297:2007 Certified

Vol. 5, Issue 4, April 2017

Silpa Krishnan currently pursuing the Bachelor's degree in Applied Electronics \& Instrumentation Engineering from the IES College of Engineering, Thrissur.

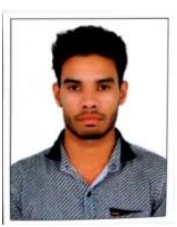

Sumith KP currently pursuing the Bachelor's degree in Applied Electronics \& Instrumentation Engineering from the IES College of Engineering, Thrissur.

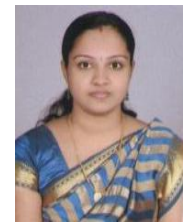

K Neethu Sathyan completed Master's Degree in Instrumentation Engineering from RVS College of Engineering \& Technology, Dindigul. She is currently working as Assistant Professor in Department of Electronics and Communication Engineering, IES College of Engineering, Thrissur. 